\title{
Correction to: Accumulation of glycine betaine in transplastomic potato plants expressing choline oxidase confers improved drought tolerance
}

Lili You ${ }^{1}$ - Qiping Song ${ }^{2}$ Y Yuyong $\mathrm{Wu}^{1}$ - Shengchun $\mathrm{Li}^{1}$. Chunmei Jiang ${ }^{1} \cdot$ Ling Chang $^{1} \cdot$ Xinghong Yang $^{2}$. Jiang Zhang ${ }^{1}$ (I)

Published online: 2 April 2019

(c) Springer-Verlag GmbH Germany, part of Springer Nature 2019

\section{Correction to: Planta}

https://doi.org/10.1007/s00425-019-03132-3

Unfortunately, the name of the second author was misspelled in the original publication. The correct spelling is Qiping Song.

The original article has been corrected.

$\triangle$ Jiang Zhang

zhangjiang@hubu.edu.cn

1 State Key Laboratory of Biocatalysis and Enzyme

Engineering, College of Life Sciences, Hubei University,

Wuhan 430062, China

2 College of Life Science, State Key Laboratory of Crop

Biology, Shandong Key Laboratory of Crop Biology,

Shandong Agricultural University, Taian 271018, China 